\title{
PENYULUHAN HUKUM PERLINDUNGAN ANAK BAGI PARA SISWA DAN GURU SDN CEMPAKA BARU O5 KEMAYORAN JAKARTA PUSAT
}

\author{
Derta Rahmanto $^{1)}$, Endang Purwaningsih ${ }^{2)}$, Evie Rachmawati Nur Ariyanti ${ }^{3)}$ \\ ${ }^{1,2,3)}$ Fakultas Hukum Universitas YARSI, Jakarta \\ $e$-mail : ${ }^{2)}$ e.purwaningsih@yarsi.ac.id
}

\begin{abstract}
Abstrak
Pada umumnya semua siswa dan guru di SDN Cempaka Baru 05 Kemayoran belum memahami secara benar tentang perlindungan anak dan penegakan hukumnya. Mereka juga belum pernah mendapatkan penyuluhan atau pelatihan tentang hukum perlindungan anak. Untuk itulah perlu diberikan pengetahuan yang cukup melalui penyuluhan hukum ini untuk mengatasi permasalahan mitra terkait upaya pencegahan kejahatan terhadap anak didik sebagai bentuk perlindungan hukum menurut UU Perlindungan anak. Upaya yang dilakukan melalui penyuluhan hukum ini dilakukan dengan memberi pengetahuan hukum tentang perlindungan anak kepada siswa dan guru, kemudian dilanjutkan pada tanya jawab, dengan metode kegiatan ceramah dan diskusi di sekolah setempat dan memberikan pre test dan post test. Hasil kegiatan menunjukkan pentingnya kegiatan penyuluhan tentang perlindungan anak untuk meningkatkan wawasan pengetahuan dan kesadaran hukum anak didik, demikian pula bagi guru sebagai pendidik, terkait tugas, hak dan kewajibannya di sekolah.
\end{abstract}

Kata Kunci : penyuluhan hukum, perlindungan, anak, siswa dan guru

\section{PENDAHULUAN}

Anak adalah titipan atau amanah dari Tuhan kepada manusia untuk dijaga dan dirawat sebaik mungkin supaya menjadi manusia yang baik dan berguna bagi masyarakat dan bangsa. Dalam pertimbangan UU nomor nomor 17 tahun 2016 dinyatakan tentang Penetapan peraturan pemerintah pengganti undang-undang nomor 1 tahun 2016 tentang perubahan kedua atas undang-undang nomor 23 tahun 2002 tentang perlindungan anak, perubahan pertama Nomor 35 Tahun 2014 tentang Perubahan atas Undang-Undang Nomor 23 Tahun 2002 tentang Perlindungan Anak yang salah satu perubahannya menitikberatkan pada pemberatan sanksi pidana terhadap pelaku kekerasan seksual terhadap anak. Namun, perubahan Undang-Undang tersebut belum menurunkan tingkat kekerasan seksual terhadap anak secara signifikan. Oleh karena itu, Negara perlu mengambil langkah-langkah yang optimal dan komprehensif dengan tidak hanya memberikan pemberatan sanksi pidana, juga menerapkan bentuk pencegahan (preventif) dengan memberikan tindakan berupa kebiri kimia, pemasangan alat pendeteksi elektronik, dan rehabilitasi bagi pelaku kekerasan seksual terhadap anak.Untuk menyikapi fenomena kekerasan seksual terhadap anak, memberi efek jera terhadap pelaku, dan mencegah terjadinya kekerasan seksual terhadap anak, Presiden telah menetapkan Peraturan Pemerintah Pengganti Undang-Undang Nomor 1 Tahun 2016 tentang Perubahan Kedua atas Undang-Undang Nomor 23 Tahun 2002 tentang Perlindungan Anak pada tanggal 25 Mei 2016, Peraturan Pemerintah Pengganti Undang-Undang Nomor 1 Tahun 2016 tentang Perubahan Kedua atas Undang-Undang Nomor 23 Tahun 2002 tentang Perlindungan Anak Menjadi Undang-Undang Nomor 17 Tahun 2016.

Pasal 1 Undang-Undang Nomor 35 Tahun 2014 tentang Perubahan atas Undang-Undang Nomor 23 Tahun 2002 tentang Perlindungan Anak menyebutkan bahwa yang dimaksud dengan adalah seseorang yang belum berusia 18 (delapan belas)tahun, termasuk juga anak yang masih dalam kandungan. Perlindungan Anak adalah segala kegiatan untuk menjamin dan melindungi anak dan hak-haknya agar dapat hidup, tumbuh, berkembang, dan berpartisipasi secara optimal sesuai dengan harkat dan martabat kemanusiaan, serta mendapat perlindungan dari kekerasan dan diskriminasi. Lahirnya revisi UU tersebut menegaskan pentingnya pemberatan sanksi pidana dan denda bagi pelaku kejahatan terhadap anak terutama kepada kejahatan 
seksual yang bertujuan untuk memberikan efek jera, serta mendorong adanya langkah konkrit untuk memulihkan kembali fisik, psikis dan sosial anak.

Orangtua bertanggungjawab atas pendidikan anak, kesehatan dan keselamatannya. Demikian pula ketika anak menjadi siswa di suatu sekolah, para guru menjadi pengganti orangtua mengambil peran dan bertanggungjawab terhadap anak saat berada dalam lingkungan sekolah. Anak, orangtua dan guru memiliki hak dan kewajiban dalam penyelenggaraan pendidikan anak dan menjamin keselamatannya dengan baik. Banyaknya kasus anak menjadi target atau korban kejahatan menjadi masalah yang sangat memprihatinkan bagi banyak pihak. Anak dan orangtua juga guru perlu diberi bekal pengetahuan yang cukup untuk bisa melindungi diri dan anak didik supaya terhindar dari hal-hal yang merugikannya atau menyakitinya.

Sosialisasi regulasi dan edukasi sejak dini perlu dilakukan kepada guru dan anak didik. Regulasi dan penegakan hukumnya yang makin tegas dan berat juga perlu agar membuat efek jera. Semua demi mengantisipasi agar anak tidak menjadi korban kejahatan dan tidak menjadi pelaku kejahatan. Fakta yang terungkap pada saat pelaku kejahatan terhadap anak utamanya pelaku pedofil/kejahatan seksual diperiksa di persidangan, ada beberapa pelaku yang mengaku pernah mengalami tindakan pelecehan seksual saat masih kecil.

Berdasarkan wawancara yang telah dilakukan oleh tim pada hari Kamis tanggal 23 Maret 2017 dengan Kepala Sekolah SDN Cempaka Baru 05, kondisi para siswa saat ini terlindungi dengan baik, namun memang belum pernah mendapatkan pencerahan atau edukasi mengenai hukum perlindungan anak, juga para gurunya. Selain itu Kepala Sekolah memandang sangat penting kegiatan edukasi ini dilakukan untuk membekali anak agar selalu berhati-hati dan bertambah wawasan. Dengan fakta inilah, tim Fakultas Hukum Universitas YARSI merasa perlu dan segera bersiaga untuk membantu memberi pencerahan kepada para peserta didik dan para guru. Untuk itulah perlu diberikan pengetahuan yang cukup melalui penyuluhan hukum ini untuk mengatasi permasalahan yakni bagaimanakah upaya pencegahan kejahatan dilakukan terhadap anak didik sebagai bentuk perlindungan hukum menurut UU Perlindungan anak.

\section{METODE KEGIATAN}

Kegiatan ini dilaksanakan dengan menggunakan metode ceramah dan tanya jawab. Metode ini digunakan untuk menyampaikan materi penyuluhan yang bersifat ringan dan menyenangkan untuk anak didik dan muatan normatif untuk guru. Pelaksanaan metode ini digunakan waktu sebanyak $40 \%$ untuk ceramah atau penyampaian materi, sedangkan sisanya $60 \%$ digunakan untuk diskusi dan tanya jawab. Selain itu juga dilakukan pre test dan post test.

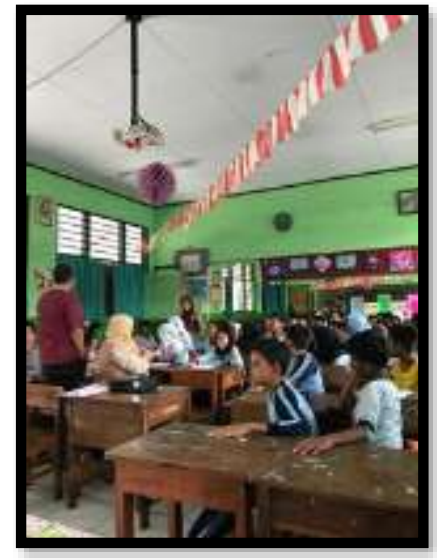

\section{HASIL DAN PEMBAHASAN}

Kegiatan penyuluhan dilakukan di SDN 05 Cempaka Baru, dengan diikuti 109 peserta baik dari guru maupun para siswa. Guru berjumlah 20 orang dan siswa 89 orang. Peserta sangat antusias memperhatikan dan aktif tanya jawab.

Tabel 1

Pemahaman tentang hak-hak anak yang harus dilindungi

\begin{tabular}{|c|r|r|}
\hline $\begin{array}{l}\text { Jawaban } \\
\text { responden }\end{array}$ & $\begin{array}{c}\text { Frequency sebelum } \\
\text { penvuluhan }\end{array}$ & $\begin{array}{c}\text { Frequenc } \\
\text { y setelah } \\
\text { penyuluh } \\
\text { an }\end{array}$ \\
\hline Valid 1.00 & 15 & 2 \\
2.00 & 64 & 4 \\
3.00 & 26 & 24 \\
4.00 & 3 & 65 \\
5.00 & 1 & 14 \\
Total & 109 & 109 \\
\hline
\end{tabular}

Berdasarkan tabel di atas dapat dipahami bahwa pemahaman khalayak sasaran tentang hak-hak anak yang harus dilindungi pada saat sebelum penyuluhan 
masih sangat rendah akan tetapi setelah penyuluhan sudah sangat baik. Dari 109 orang, sedikitnya sudah ada 14 orang yang sudah sangat memahmi, 65 sudah paham, dan 24 orang sudah cukup paham. Sisanya sebanyak 6 orang belum paham dan sangat tidak paham.

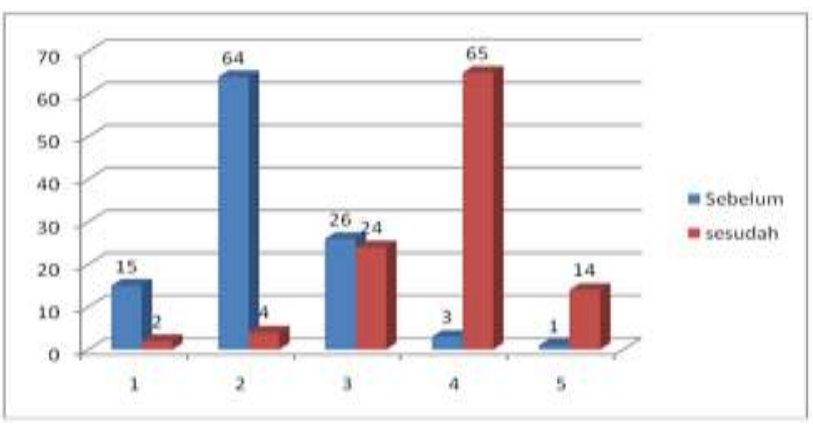

Diagram 1

Pemahaman tentang hak-hak anak yang harus dilindungi

Tabel 2.

Pemahaman tentang kewajiban orang tua terhadap anak

\begin{tabular}{|c|c|c|c|}
\hline \multirow{2}{*}{ Valid } & $\begin{array}{c}\text { Jawaban } \\
\text { responden }\end{array}$ & $\begin{array}{c}\text { Frequency } \\
\text { sebelum } \\
\text { penyuluhan }\end{array}$ & $\begin{array}{c}\text { Frequency setelah } \\
\text { penyuluhan }\end{array}$ \\
\cline { 2 - 4 } & 2.00 & 42 & 6 \\
\cline { 2 - 4 } & 3.00 & 34 & 16 \\
\cline { 2 - 4 } & 4.00 & 20 & 47 \\
\cline { 2 - 4 } & 5.00 & 3 & 40 \\
\hline Total & 109 & 109.0 \\
\hline
\end{tabular}

Berdasarkan tabel di atas dapat diketahui bahwa pemahaman khalayak sasaran tentang kewajiban orang tua terhadap anak antara sebelum dan sudah penyuluhan terjadi peningkatan yang berarti. Sesudah penyuluhan sedikitnya ada 40 orang yang sudah sangat paham, sebanyak 47 orang sudah paham, dan sebanyak 16 orang sudah cukup paham. Sisanya sebanyak 6 orang belum paham.

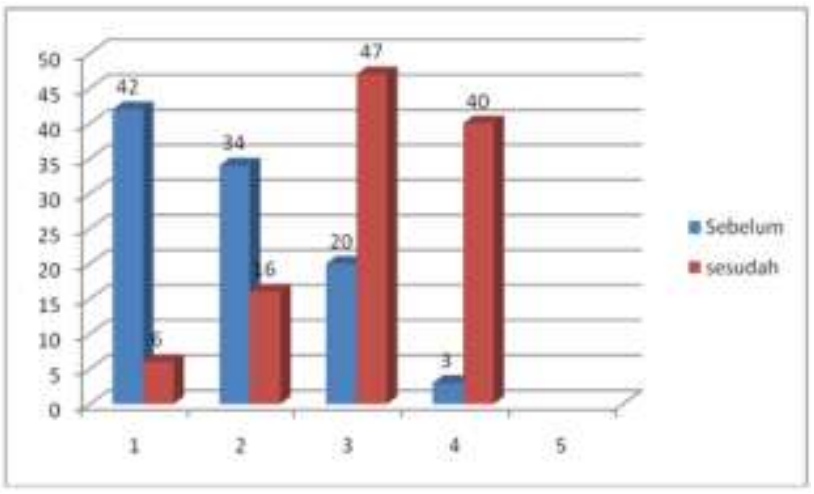

Diagram 2

Pemahaman tentang kewajiban orang tua terhadap anak
Tabel 3

Pemahaman tentang Keberadaan UU tentang Perlindungan anakdan UU guru dan Dosen

\begin{tabular}{|l|l|r|r|}
\hline & $\begin{array}{l}\text { Jawaban } \\
\text { responden }\end{array}$ & \multicolumn{1}{|c|}{$\begin{array}{c}\text { Frequency } \\
\text { sebelum } \\
\text { penyuluhan }\end{array}$} & $\begin{array}{c}\text { Frequency } \\
\text { setelah } \\
\text { penyuluhan }\end{array}$ \\
\hline \multirow{5}{*}{ Valid } & 1.00 & 25 & 3 \\
\cline { 2 - 4 } & 2.00 & 40 & 19 \\
\cline { 2 - 4 } & 3.00 & 24 & 38 \\
\cline { 2 - 4 } & 4.00 & 15 & 14 \\
\cline { 2 - 4 } & 5.00 & 5 & 109.0 \\
\cline { 2 - 4 } & Total & 109 & 35 \\
\hline
\end{tabular}

Berdasarkan tabel di atas dapat diketahui bahwa telah terjadi peningkatan pemahaman yang sangat berarti antara sebelum dan sesudah penyuluhan tentang Keberadaan UU tentang Perlindungan anak dan UU guru dan Dosen. Sesudah penyuluhan, ada sebanyak 14 orang yang sudah sangat paham tentang keberadaan kedua UU tersebut. Ada sebanyak 35 orang yang sudah paham, dan sebanyak 38 orang sudah cukup paham. Sisanya ada sebanyak 21 orang masih kurang paham.

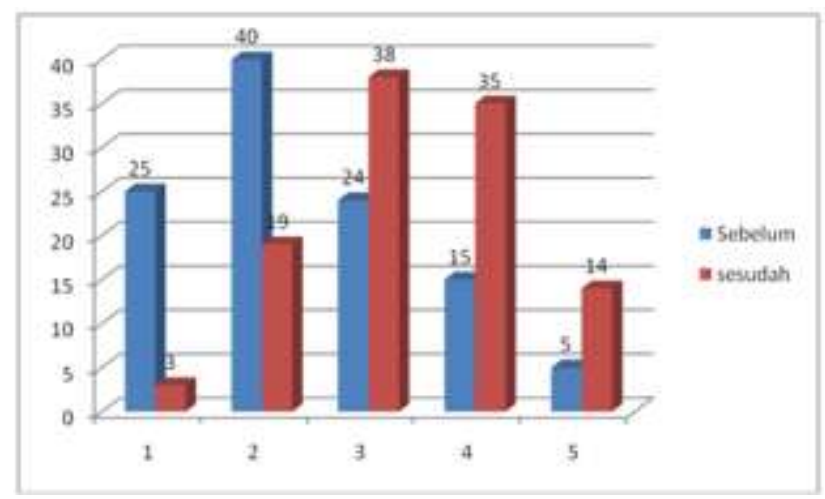

Diagram 3

Pemahaman tentang kewajiban orang tua terhadap anak

Tabel 4

Pemahaman tentang Kewajiban Guru di Sekolah

\begin{tabular}{|l|l|r|r|}
\hline \multirow{2}{*}{ Valid } & $\begin{array}{l}\text { Jawaban } \\
\text { responden }\end{array}$ & \multicolumn{1}{|c|}{$\begin{array}{c}\text { Frequency } \\
\text { sebelum } \\
\text { penyuluhan }\end{array}$} & $\begin{array}{l}\text { Frequency setelah } \\
\text { penyuluhan }\end{array}$ \\
\hline \multirow{5yyy}{*}{} & 2.00 & 45 & 5 \\
\cline { 2 - 4 } & 3.00 & 34 & 13 \\
\cline { 2 - 4 } & 4.00 & 26 & 56 \\
\cline { 2 - 4 } & 5.00 & 4 & 35 \\
\cline { 2 - 4 } & Total & 109 & 109 \\
\hline
\end{tabular}

Tabel di atas memberikan informasi bahwa pemahaman tentang Kewajiban Guru di Sekolah yang dirasakan oleh khalayak sasaran berbeda-beda. Akan 
tetapi, telah terjadi peningkatan yang sangat berarti, karena setelah penyuluhan, ada sebanyak 35 orang yang sudah sangat paham tentang Kewajiban Guru di Sekolah, sebanyak 35 orang sudah paham, dan 56 orang sudah cukup paham. Sisanya sebanyak 18 orang belum begitu paham tentang Kewajiban Guru di Sekolah.

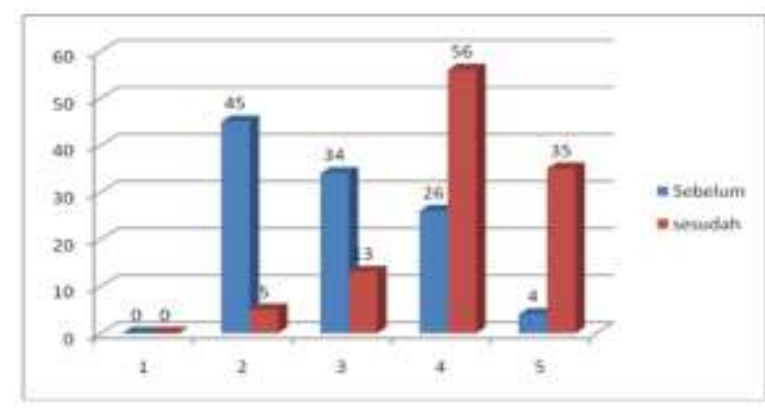

Diagram 4

Pemahaman tentang Kewajiban Guru di Sekolah

Tabel 5

Pemahaman tentang Kewajiban Anak di Sekolah

\begin{tabular}{|c|c|c|c|}
\hline & $\begin{array}{l}\text { Jaxiban } \\
\text { responden }\end{array}$ & $\begin{array}{c}\text { Frequency sebelum } \\
\text { oenvuluhan }\end{array}$ & $\begin{array}{l}\text { Frequency setelah } \\
\text { Denvuluhan }\end{array}$ \\
\hline \multirow[t]{5}{*}{ Valid } & 2.00 & 54 & 3 \\
\hline & 3.00 & 44 & 12 \\
\hline & 4.00 & 10 & 42 \\
\hline & 5.00 & 1 & 52 \\
\hline & Total & 109 & 109 \\
\hline
\end{tabular}

Mencermati tabel hasil pengabdian di atas, dapat dipahami bahwa pemahaman tentang kewajiban anak di sekolah yang dipahami oleh peserta penyuluhan adalah, bahwa sudah ada sebanyak 52 orang yang sudah sangat memahami tentang kewajiban anak di sekolah. Sebanyak 42 orang sudah paham, dan sebanyak 12 orang sudah cukup paham tentang kewajiban anak di sekolah, namun demikian, masih ada sebanyak 3 orang yang kurang begitu paham tentang kewajiban anak di sekolah.

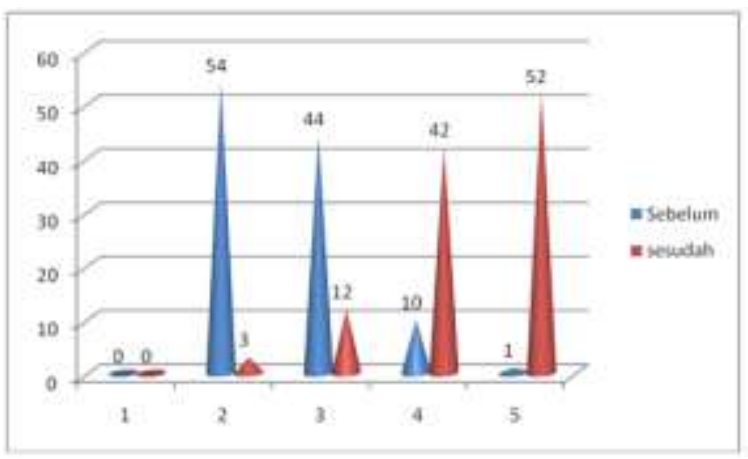

\section{Diagram 5}

Pemahaman tentang Kewajiban Anak di Sekolah

\section{KESIMPULAN}

Upaya pencegahan kejahatan terhadap anak didik sebagai bentuk perlindungan hukum menurut UU Perlindungan Anak dapat dilakukan dengan mensosialisasi regulasi, mengedukasi anak didik dan pihak terkait seperti halnya guru dan orangtua, agar anak didik mampu menjaga diri dan pihak terkait dapat memberi daya dukung positif bagi perlindungan anak.

Kegiatan penyuluhan tentang perlindungan anak sangat penting dilakukan untuk menambah wawasan pengetahuan dan kesadaran hukum anak, khususnya anak didik di SDN 05 Cempaka Baru, demikian pula bagi guru sebagai pendidik, terkait tugas, hak dan kewajibannya di sekolah. Kegiatan penyuluhan hukum ini mampu meningkatkan tingkat pengetahuan hukum peserta, namun harus tetap diingatkan kembali dengan terus mengedukasi para peserta dengan baik.

\section{REFERENSI}

Paska, Anastasia Ayu. Jurnal Hukum Gloria Juris vol.9 no.1 Januari-April 2009

FH UNIKA Atmajaya

Wright, Richard W., Grounds and Extent of Legal Responsibility, (San Diego Law

Review: 2013

Woman's human right monitoring report 2007 Komnas Perempuan RI

UU Nomor 17 Tahun 2016 juncto UU Nomor 35 Tahun 2014 juncto UU Nomor 23 Tahun 2002 Tentang Perlindungan Anak 